\title{
A formação e a vivência dos profissionais de saúde frente ao processo de morte e morrer em pediatria: Uma revisão integrativa
}

\author{
The training and experience of health professionals facing the process of death and dying in \\ pediatrics: An integrative review \\ La formación y experiencia de los profesionales sanitarios ante el proceso de muerte y morir en \\ pediatría: Una revisión integradora
}

Recebido: 01/06/2021 | Revisado: 06/07/2021 | Aceito: 08/07/2021 | Publicado: 20/07/2021

Thamires Goulart Lambranho de Azevedo
ORCID: https://orcid.org/0000-0003-3320-4504
Instituto Nacional de Saúde da Mulher, da Criança e do Adolescente Fernandes Figueira, Brasil
E-mail: goularthamires4@ gmail.com
Bruna Santos Ferreira Lima
ORCID: https://orcid.org/0000-0002-2489-7540
E-mail: enfebsan@ @mail.com
Elena Araujo Martinez
Instituto Nacional de Saúde da Mulher, da Criança e do Adolescente Fernandes Figueira, Brasil
ORCID: https://orcid.org/0000-0002-3155-102X
E-mail: elena.araujo.martinez@gmail.com

\section{Resumo}

Este trabalho teve como objetivo analisar as evidências encontradas na literatura científica nacional e internacional, no que concerne ao processo de morte e morrer em pediatria frente formação acadêmica e vivência prática dos profissionais de saúde. Trata-se de uma revisão integrativa, suportada na recomendação PRISMA. A busca foi realizada de agosto a dezembro de 2020, por meio das bases de dados: PubMed, LILACS, Scielo e CINAHL, aplicando os seguintes filtros: artigos completos publicados entre 2010 a 2020, nos idiomas inglês, português e espanhol e utilizando-se os descritores: "morte/death", pessoal de saúde/health personnel", "criança/child", "equipe de assistência ao paciente/patient care team". A amostra final do estudo foi composta por 26 artigos. Na análise das publicações os artigos foram classificados em três unidades de análise, quais sejam: o processo de formação como facilitador para lidar com o processo de morte e morrer, a vivência dos profissionais diante do luto da família em pediatria e terminalidade e cuidados paliativos em pediatria. O estudo permitiu afirmar que o fato da morte ainda ser considerada um tabu para a sociedade acaba por perpetuar a falta de discussão e reflexão sobre o processo de morte e morrer no meio acadêmico. Desta forma, os profissionais de saúde não se sentem efetivamente capacitados para lidar com o processo de morte e morrer em pediatria, principalmente pela falta de contato com esta temática durante a graduação e até mesmo na pós-graduação e posteriormente, pela falta de apoio nas instituições assistenciais.

Palavras-chave: Morte; Pessoal de saúde; Criança; Equipe de assistência ao paciente.

\begin{abstract}
This study aimed to analyze the evidence found in the national and international scientific literature, regarding the process of death and dying in pediatrics in terms of academic training and practical experience of health professionals. This is an integrative review, supported by the PRISMA recommendation. The search was carried out from August to December 2020, through the databases: PubMed, LILACS, Scielo and CINAHL, applying the following filters: full articles published between 2010 and 2020, in English, Portuguese and Spanish and using the descriptors: "death/death", health personnel/health personnel", "child/child", "patient care team/patient care team". The final study sample consisted of 26 articles. In analyzing the publications, the articles were classified into three units of analysis, namely: the training process as a facilitator to deal with the process of death and dying, the experience of professionals in the face of family grief in pediatrics and terminality and palliative care in pediatrics. The study allowed us to state that the fact that death is still considered a taboo for society ends up perpetuating the lack of discussion and reflection on the process of death and dying in academia. Thus, health professionals do not feel effectively able to deal with the process
\end{abstract}


of death and dying in pediatrics, mainly due to the lack of contact with this issue during undergraduate and even graduate studies and later, due to the lack of support in care institutions.

Keywords: Death; Health personnel; Child; Patient care team.

\section{Resumen}

Este estudio tuvo como objetivo analizar la evidencia encontrada en la literatura científica nacional e internacional, sobre el proceso de muerte y morir en pediatría en términos de formación académica y experiencia práctica de los profesionales de la salud. Esta es una revisión integradora, respaldada por la recomendación PRISMA. La búsqueda se realizó de agosto a diciembre de 2020, a través de las bases de datos: PubMed, LILACS, Scielo y CINAHL, aplicando los siguientes filtros: artículos completos publicados entre 2010 y 2020, en inglés, portugués y español y utilizando los descriptores: "muerte / muerte", personal de salud / personal de salud", "niño / niño", "equipo de atención al paciente / equipo de atención al paciente". La muestra final del estudio estuvo formada por 26 artículos. Al analizar las publicaciones, los artículos se clasificaron en tres unidades de análisis, a saber: el proceso de formación como facilitador para afrontar el proceso de muerte y morir, la experiencia de los profesionales ante el duelo familiar en pediatría y terminalidad y cuidados paliativos. en pediatría. El estudio permitió afirmar que el hecho de que la muerte todavía se considere un tabú para la sociedad termina perpetuando la falta de discusión y reflexión sobre el proceso de la muerte y el morir en la academia. Así, los profesionales de la salud no se sienten efectivamente capacitados para afrontar el proceso de muerte y morir en pediatría, principalmente por la falta de contacto con este tema durante los estudios de pregrado e incluso de posgrado y posteriormente, por la falta de apoyo en las instituciones de atención.

Palabras clave: Muerte; Personal sanitario; Niño; Equipo de atención al paciente.

\section{Introdução}

O final da vida define-se como um momento extremamente complexo, controverso e polêmico, pois envolve todas as pessoas em todas as sociedades, uma vez que todos terão de enfrentar seu próprio fim da vida. Porém, ainda que os seres humanos temam a morte, em algumas circunstâncias, esta pode trazer alívio pelo fim do sofrimento. Já para os profissionais de saúde, a morte de pacientes gera frustração, sensação de derrota e de incapacidade, principalmente quando o foco da assistência é a saúde da criança (Souza \& Conceição, 2018).

A morte para a maioria dos profissionais de saúde é sinônimo de não êxito. Quando ela acontece, a interpretam como uma sensação ou sentimento de fracasso. E isto é uma consequência da formação acadêmica, pois os profissionais são instruídos a dar continuidade à vida e muitas vezes não são preparados para encarar a morte como um processo natural e universal. Além disso, o modelo de atenção à saúde vigente baseia-se em prevenção, diagnóstico, tratamento efetivo e cura de doenças, porém diante da incurabilidade de determinadas doenças esse modelo se mostra pouco eficaz (Alves, et al., 2012; Lima, et al., 2017).

Sabe-se que a morte é um fato inevitável, porém é difícil aceitar que esta aconteça precocemente, principalmente nos primeiros anos de vida. Sendo assim, lidar com este assunto torna-se uma questão extremamente delicada, tanto para os profissionais, quanto para a família desta clientela. Além disso, a morte durante a infância é uma situação que não pode sequer ser pensada pela família, pois o natural seria que os pais morressem antes das crianças, na perspectiva do ciclo vital (Poles \& BOUSSO, 2006).

Em princípio, há carência de debates sobre o processo de morte e morrer em toda a formação pedagógica, incluindo as escolas de ensino fundamental, médio e superior, demandando ampliação do escopo da educação para a morte, em face da interdição do tema. Ainda existem muitos desafios a serem enfrentados na formação, tais como as limitações nos currículos das escolas sobre a terminalidade, especialmente em ambientes multiculturais (Lima, et al., 2017).

A morte está presente no cotidiano dos profissionais de saúde, mas o preparo formal ainda é insuficiente, com ensino voltado para a tecnociência, mas com pouco espaço para a abordagem dos aspectos emocionais, espirituais e sociais do ser humano. Além disso, é preciso considerar que os profissionais também sofrem nesse processo, pois falar sobre terminalidade exige-lhes grande esforço cognitivo e emocional, pois essa linguagem não lhes foi ensinada ou o foi de forma incipiente, no 
processo pedagógico de formação. Não há investimento adequado e suficiente no processo de formação, tanto de nível técnico quanto de nível superior que lhes permita interpretar os sentimentos que emergem nesse momento (Lima, et al., 2017).

Diante do exposto, esta pesquisa teve como objetivo analisar as evidências encontradas na literatura científica nacional e internacional, no que concerne ao processo de morte e morrer em pediatria frente formação acadêmica e vivência prática dos profissionais de saúde.

\section{Metodologia}

Trata-se de uma revisão integrativa de literatura, que pode ser definida como a mais ampla abordagem metodológica referente às revisões, concedendo a inclusão de estudos experimentais e não-experimentais para uma compreensão completa do fenômeno a ser analisado. Este estudo foi desenvolvido em seis etapas: 1) elaboração da questão de pesquisa, 2) estabelecimento de critérios para inclusão e exclusão de estudos ou busca na literatura, 3) categorização dos estudos, 4) avaliação dos estudos incluídos na revisão integrativa, 5) interpretação dos resultados e 6) apresentação da revisão do conhecimento (Souza, et al., 2010; Whittemore, et al., 2005).

A pesquisa surgiu da seguinte questão norteadora: “o que as produções científicas abordam sobre a formação acadêmica e vivência prática dos profissionais de saúde frente ao processo de morte e morrer na assistência à criança?”. A pergunta de pesquisa foi construída com base na estratégia PICo (acrômio "P”: problema; "I": intervenção; e "Co": contexto), utilizando "formação acadêmica e vivência prática dos profissionais de saúde" para o acrômio "P"; "enfrentamento do processo de morte e morrer" para "I"; e "na assistência à criança" para "Co".

Para a realização da busca, foram utilizados os descritores em ciências da saúde (DECs): “morte/death”, "pessoal de saúde/health personnel”, “criança/child”, “equipe de assistência ao paciente/patient care team”.

A busca pelos artigos foi realizada no período de agosto a dezembro de 2020, por meio das seguintes fontes de informação online: U.S. National Library of Medicine National Institute of Health (PubMed), Literatura Latino Americana e Ciências do Caribe (LILACS), Scielo e CINAHL, aplicando os seguintes filtros: artigos completos publicados entre 2010 a 2020 , nos idiomas inglês, português e espanhol.

Para a realização da busca, os DECs foram combinados entre si utilizando o operador boleano "AND”. Para as bases que utilizavam prioritariamente o inglês, os descritores foram combinados no mesmo idioma, compatíveis com o MeSH (Medical Subject Headings).

Mediante a pesquisa os critérios de elegebilidade adotados no estudo foram: artigos originais, de revisão ou observacionais que versavam sobre a perspectiva do processo morte e morrer com foco nos profissionais de saúde. Já os de exclusão: publicações repetidas nas bases de dados; teses; artigos de reflexão, além de artigos sem aderência a temática.

Ao realizar o levantamento nas bases de dados e após a aplicação dos filtros identificaram-se 578 publicações. Desconsiderou-se os estudos duplicados para leitura seletiva por meio de título e resumo resultando em 497 publicações, com posterior exclusão de 365 por não aderirem a temática. Desta forma, foram selecionados para leitura na integra 132 publicações. Por fim, mediante a aplicação dos critérios de elegibilidade foram selecionados para compor a amostra 26 artigos. Na Figura 1 está representado o fluxograma da seleção dos estudos, conforme as recomendações PRISMA.

Os dados dos estudos selecionados foram organizados em um quadro, a partir das seguintes informações: ano/idioma/base de dados, título, objetivos, método e principais resultados. 
Figura 1. Fluxo do processo de seleção dos estudos para a revisão integrativa, elaborado com base nas recomendações PRISMA. Rio de Janeiro, RJ, 2020.

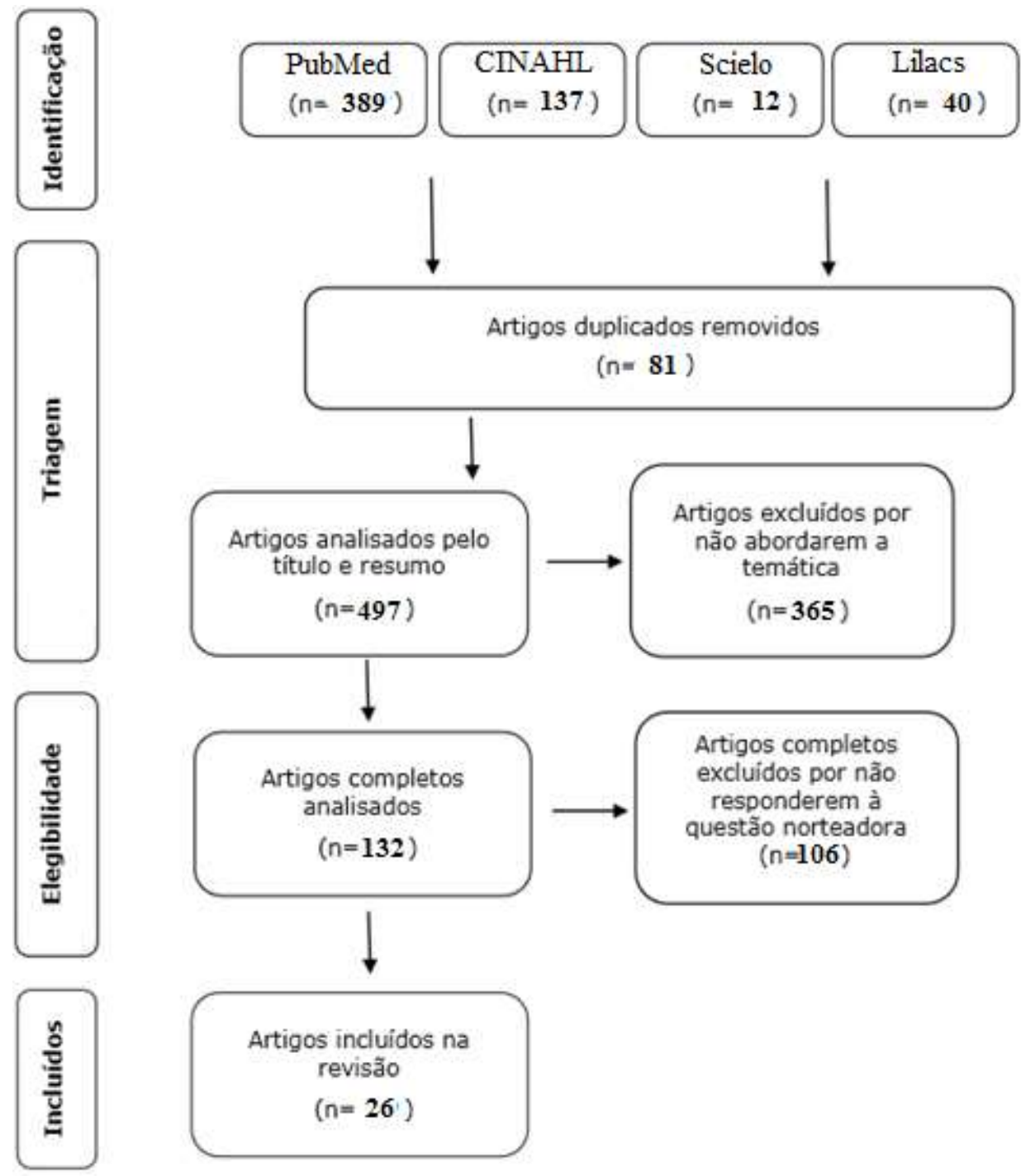

Fonte: adaptado de THE PRISMA Group (2015).

\section{Resultados}

Esta revisão integrativa contemplou vinte e seis artigos que atenderam rigorosamente a seleção previamente estabelecida da amostra dispostos no quadro 1, sendo 8 artigos encontrados na base de dados Pubmed, 7 artigos encontrados na LILACS, 5 na Scielo e 6 artigos na base de dados CINAHL.

O idioma que mais predominou nesta busca foi o inglês, correspondendo a aproximadamente $61 \%$ das publicações (16 artigos), seguido do português com $31 \%$ dos estudos (8 artigos) e espanhol com apenas duas publicações. Cerca de dez estudos trabalharam com uma categoria profissional específica, geralmente enfermagem (7 artigos) ou medicina (3 artigos). Quatorze artigos (53\% das publicações) discutiam a formação profissional ou a vivência da equipe multidisciplinar frente ao processo de morte e morrer.

Observa-se a diversidade das publicações com relação ao recorte temporal, sendo a maioria dos artigos publicados durante os últimos seis anos, com destaque para 2015 e 2019, ambos com cinco publicações. Cerca de 18 trabalhos (69\% dos estudos) eram qualitativos e a maioria utilizou o roteiro semi-estruturado para compor a metodologia. O método que menos se destacou foi o quantitativo, com apenas duas publicações. 
Parte dos estudos (7 artigos, aproximadamente $27 \%$ das publicações) abordavam o processo de morte e o morrer em oncologia pediátrica, principalmente focando em crianças diagnosticadas com leucemia e abordando a temática dos cuidados paliativos. Cerca de sete publicações ( $27 \%$ dos estudos) apresentavam a unidade de terapia intensiva pediátrica (UTIP) ou a unidade de terapia intensiva neonatal (UTIN) como cenário.

Além da carência de debates sobre este tema durante a formação profissional, também se observou durante a busca que apenas quatro artigos sobre terminalidade discutiam o processo de formação, sendo a maioria deles voltados para compreender a vivência e os sentimentos da equipe frente a finitude e/ou para discutir o luto familiar e suas consequências.

Quadro 1. Caracterização da produção científica com relação ao processo de morte e morrer na formação dos profissionais. Rio de Janeiro, RJ, 2020.

\begin{tabular}{|c|c|c|c|c|c|}
\hline $\mathbf{N}^{\mathbf{0}}$ & $\begin{array}{c}\text { Ano/ } \\
\text { Idioma/Base } \\
\text { de dados }\end{array}$ & Título & Objetivos & Método & Principais resultados \\
\hline 1 & $\begin{array}{l}2019 \\
\text { Português } \\
\text { Lilacs }\end{array}$ & $\begin{array}{l}\text { Percepções da equipe } \\
\text { interdisciplinar sobre } \\
\text { cuidados paliativos } \\
\text { em oncologia } \\
\text { pediátrica }\end{array}$ & $\begin{array}{l}\text { Compreender as percepções } \\
\text { da equipe interdisciplinar da } \\
\text { Unidade de Oncologia } \\
\text { Pediátrica sobre cuidados } \\
\text { paliativos no contexto do } \\
\text { câncer infantil }\end{array}$ & $\begin{array}{l}\text { Estudo } \\
\text { exploratório } \\
\text { descritivo }\end{array}$ & $\begin{array}{l}\text { Destaca-se a necessidade de criar } \\
\text { espaços de discussões teóricas sobre } \\
\text { morte e cuidados paliativos, bem } \\
\text { como de encontros sistemáticos para } \\
\text { abordar as percepções relacionadas ao } \\
\text { cuidado desses pacientes. }\end{array}$ \\
\hline 2 & $\begin{array}{l}2019 \\
\text { Português } \\
\text { Lilacs }\end{array}$ & $\begin{array}{l}\text { Do diagnóstico a } \\
\text { terminalidade: } \\
\text { enfrentamento da } \\
\text { equipe } \\
\text { multiprofissional na } \\
\text { oncologia pediátrica }\end{array}$ & $\begin{array}{l}\text { Identificar as percepções e } \\
\text { sentimentos que permeiam } \\
\text { a assistência da equipe } \\
\text { multiprofissional no câncer } \\
\text { infantil. }\end{array}$ & $\begin{array}{l}\text { Pesquisa } \\
\text { qualitativa, } \\
\text { prospectiva } \\
\text { e descritiva }\end{array}$ & $\begin{array}{l}\text { A equipe multiprofissional acaba } \\
\text { defrontando-se diariamente com } \\
\text { expectativas, medos e angústias frente } \\
\text { à incerteza de cura e a morte na } \\
\text { criança, afetando diretamente a saúde } \\
\text { psíquica do trabalhador. }\end{array}$ \\
\hline 3 & $\begin{array}{l}2015 \\
\text { Inglês } \\
\text { Lilacs }\end{array}$ & $\begin{array}{l}\text { Cuidados paliativos } \\
\text { em oncologia } \\
\text { pediátrica: } \\
\text { percepções, saberes e } \\
\text { práticas na } \\
\text { perspectiva da equipe } \\
\text { multiprofissional }\end{array}$ & $\begin{array}{l}\text { Conhecer as percepções, } \\
\text { saberes e práticas da equipe } \\
\text { multiprofissional na atenção } \\
\text { às crianças em cuidados } \\
\text { paliativos em unidade de } \\
\text { oncologia pediátrica. }\end{array}$ & $\begin{array}{l}\text { Pesquisa } \\
\text { qualitativa, } \\
\text { exploratória } \\
\text { e descritiva }\end{array}$ & $\begin{array}{l}\text { Emergiram quatro temas intitulados: } \\
\text { cuidados paliativos concepções da } \\
\text { equipe multiprofissional; a construção } \\
\text { de um cuidado singular; as facilidades } \\
\text { e as dificuldades vivenciadas pela } \\
\text { equipe e aprendizagens significativas. }\end{array}$ \\
\hline 4 & $\begin{array}{l}2013 \\
\text { Inglês } \\
\text { Lilacs }\end{array}$ & $\begin{array}{l}\text { Significados } \\
\text { atribuídos pela equipe } \\
\text { de enfermagem em } \\
\text { unidade de terapia } \\
\text { intensiva pediátrica ao } \\
\text { processo de morte e } \\
\text { morrer }\end{array}$ & $\begin{array}{l}\text { Compreender os } \\
\text { sentimentos vivenciados } \\
\text { pela enfermagem diante da } \\
\text { morte do paciente } \\
\text { pediátrico. }\end{array}$ & $\begin{array}{l}\text { Pesquisa de } \\
\text { natureza } \\
\text { qualitativa, } \\
\text { descritiva e } \\
\text { exploratória }\end{array}$ & $\begin{array}{l}\text { A temática da morte permanece } \\
\text { pouco explorada e discutida na } \\
\text { formação profissional e a organização } \\
\text { de serviços de apoio específicos nas } \\
\text { instituições poderia contribuir para } \\
\text { uma atenção mais qualificada nesse } \\
\text { contexto. }\end{array}$ \\
\hline 5 & $\begin{array}{l}2013 \\
\text { Português } \\
\text { Lilacs }\end{array}$ & $\begin{array}{l}\text { Morte digna da } \\
\text { criança: percepção de } \\
\text { enfermeiros de uma } \\
\text { unidade de oncologia }\end{array}$ & $\begin{array}{l}\text { Identificar o significado e } \\
\text { as intervenções de } \\
\text { enfermeiros que atuam em } \\
\text { oncologia pediátrica na } \\
\text { promoção de morte digna } \\
\text { da criança. }\end{array}$ & $\begin{array}{l}\text { Pesquisa de } \\
\text { narrativa }\end{array}$ & $\begin{array}{l}\text { Identificou-se categorias e } \\
\text { subcategorias com descrições sobre } \\
\text { morte digna, assim como as } \\
\text { intervenções pertinentes para a } \\
\text { elaboração de um cuidado mais } \\
\text { holístico que culminasse no morrer } \\
\text { dignamente. }\end{array}$ \\
\hline 6 & $\begin{array}{l}2013 \\
\text { Espanhol } \\
\text { Lilacs }\end{array}$ & $\begin{array}{l}\text { Vivência de } \\
\text { enfermeiras } \\
\text { intensivistas } \\
\text { pediátricas na morte } \\
\text { de uma criança: } \\
\text { vivências, luto, } \\
\text { aspecto bioético }\end{array}$ & $\begin{array}{l}\text { Explorar a vivência de } \\
\text { enfermeiras intensivistas } \\
\text { pediátricas na morte de uma } \\
\text { criança, incluindo sua } \\
\text { vivência, luto e aspecto } \\
\text { bioético }\end{array}$ & $\begin{array}{l}\text { Estudo } \\
\text { qualitativo } \\
\text { descritivo, } \\
\text { com } \\
\text { enfoque } \\
\text { fenomenoló } \\
\text {-gico }\end{array}$ & $\begin{array}{l}\text { A vinculação da experiência na morte } \\
\text { de um filho com a dor é marcante, } \\
\text { colocando a enfermeira a entender a } \\
\text { dor como sua. É importante ressaltar } \\
\text { que a desconexão emocional pode } \\
\text { impactar na qualidade da assistência, } \\
\text { tanto para o paciente quanto para sua } \\
\text { família. }\end{array}$ \\
\hline
\end{tabular}




\begin{tabular}{|c|c|c|c|c|c|}
\hline 7 & $\begin{array}{l}2010 \\
\text { Português } \\
\text { Lilacs }\end{array}$ & $\begin{array}{l}\text { Percepções dos } \\
\text { profissionais de } \\
\text { enfermagem intensiva } \\
\text { frente a morte do } \\
\text { recém-nascido }\end{array}$ & $\begin{array}{l}\text { Descrever as percepções } \\
\text { dos profissionais de } \\
\text { enfermagem diante da } \\
\text { morte de recém-nascidos } \\
\text { em unidade de terapia } \\
\text { intensiva neonatal }\end{array}$ & $\begin{array}{l}\text { Qualitativa } \\
\text { com } \\
\text { enfoque } \\
\text { fenomenoló } \\
\text {-gico }\end{array}$ & $\begin{array}{l}\text { Emergiram do questionamento, } \\
\text { acerca deste fenômeno, uma } \\
\text { diversidade de sentimentos, como } \\
\text { perda, compaixão, tristeza, o que } \\
\text { resulta numa experiência do mundo } \\
\text { sensível de cada profissional. }\end{array}$ \\
\hline 8 & $\begin{array}{l}2017 \\
\text { Português } \\
\text { SciELO }\end{array}$ & $\begin{array}{l}\text { A atuação do } \\
\text { profissional de saúde } \\
\text { residente em contato } \\
\text { com a morte e o } \\
\text { morrer }\end{array}$ & $\begin{array}{l}\text { Compreender a percepção } \\
\text { do residente diante da } \\
\text { atuação na morte e no } \\
\text { morrer e investigar a } \\
\text { formação sobre essa } \\
\text { temática, a experiência de } \\
\text { atuação nessas situações e o } \\
\text { aparato teórico e técnico } \\
\text { obtido }\end{array}$ & $\begin{array}{l}\text { Pesquisa de } \\
\text { natureza } \\
\text { qualitativa, } \\
\text { fundamenta- } \\
\text { da na } \\
\text { hermenêuti- } \\
\text { ca } \\
\text { fenomenoló } \\
\text {-gica }\end{array}$ & $\begin{array}{l}\text { Os resultados obtidos indicam o lugar } \\
\text { dos programas de residência na } \\
\text { tentativa de minimizar as } \\
\text { complicações da carência da } \\
\text { formação; apontam para a } \\
\text { necessidade de espaços de cuidado } \\
\text { para os profissionais; e destacam que } \\
\text { a dimensão ética do cuidado a esses } \\
\text { pacientes se sobrepôs às relações } \\
\text { técnicas. }\end{array}$ \\
\hline 9 & $\begin{array}{l}2013 \\
\text { Português } \\
\text { SciELO }\end{array}$ & $\begin{array}{l}\text { Experiência em } \\
\text { cuidados paliativos à } \\
\text { criança portadora de } \\
\text { leucemia: a visão dos } \\
\text { profissionais }\end{array}$ & $\begin{array}{l}\text { Compreender a visão da } \\
\text { equipe multidisciplinar } \\
\text { perante a criança portadora } \\
\text { de leucemia em cuidado } \\
\text { paliativo }\end{array}$ & $\begin{array}{l}\text { Estudo de } \\
\text { caso } \\
\text { qualitativo }\end{array}$ & $\begin{array}{l}\text { Verificou-se que os profissionais } \\
\text { possuem pouca experiência nessa área } \\
\text { e têm dificuldade em lidar com os } \\
\text { sentimentos, se sentindo, às vezes, } \\
\text { impossibilitados de agir mediante as } \\
\text { angústias dos envolvidos e com a } \\
\text { morte. }\end{array}$ \\
\hline 10 & $\begin{array}{l}2020 \\
\text { Espanhol } \\
\text { SciELO }\end{array}$ & $\begin{array}{l}\text { Reflexão bioética no } \\
\text { cuidado de uma } \\
\text { criança diante da } \\
\text { morte }\end{array}$ & $\begin{array}{l}\text { Refletir sobre o valor da } \\
\text { dignidade humana a partir } \\
\text { da revisão do caso de uma } \\
\text { menina em sua fase final de } \\
\text { vida }\end{array}$ & $\begin{array}{l}\text { Revisão do } \\
\text { caso }\end{array}$ & $\begin{array}{l}\text { A terminalidade é um processo de } \\
\text { difícil manejo pela equipe de saúde e } \\
\text { o cuidado nesta fase implica respeitar } \\
\text { a dignidade, fomentar a autonomia e } \\
\text { promover uma boa morte. }\end{array}$ \\
\hline 11 & $\begin{array}{l}2018 \\
\text { Português } \\
\text { SciELO }\end{array}$ & $\begin{array}{l}\text { Processo de morrer } \\
\text { em unidade de terapia } \\
\text { intensiva pediátrica }\end{array}$ & $\begin{array}{l}\text { Discutir como os } \\
\text { profissionais de } \\
\text { enfermagem lidam com o } \\
\text { processo de morte e morrer } \\
\text { e identificar os impactos } \\
\text { causados na assistência } \\
\text { durante esse processo nas } \\
\text { unidades de cuidados } \\
\text { intensivos pediátrica. }\end{array}$ & $\begin{array}{l}\text { Método } \\
\text { qualitativo e } \\
\text { exploratório } \\
\text {-descritivo }\end{array}$ & $\begin{array}{l}\text { O maior tempo de contato com o } \\
\text { paciente pediátrico, o } \\
\text { acompanhamento do } \\
\text { desenvolvimento da criança e a } \\
\text { convivência com a família acabam } \\
\text { resultando em maior dificuldade para } \\
\text { aceitar a morte. }\end{array}$ \\
\hline 12 & $\begin{array}{l}2016 \\
\text { Português } \\
\text { SciELO }\end{array}$ & $\begin{array}{l}\text { A perspectiva de } \\
\text { residentes sobre a } \\
\text { morte e seu reflexo na } \\
\text { relação com os } \\
\text { pacientes }\end{array}$ & $\begin{array}{l}\text { Discutir como são as } \\
\text { relações dos residentes com } \\
\text { pacientes sem perspectiva } \\
\text { de cura e como a } \\
\text { participação no programa } \\
\text { de residência repercute em } \\
\text { sua atuação junto a esses }\end{array}$ & $\begin{array}{l}\text { Pesquisa } \\
\text { qualitativa } \\
\text { com método } \\
\text { psicanalítico }\end{array}$ & $\begin{array}{l}\text { Nos programas de residência, as } \\
\text { reflexões vivenciadas sobre o tema da } \\
\text { morte ocorrem, sobretudo, através da } \\
\text { prática. Há uma lacuna nas disciplinas } \\
\text { acerca do tema. }\end{array}$ \\
\hline 13 & $\begin{array}{l}2015 \\
\text { Inglês } \\
\text { Pubmed }\end{array}$ & $\begin{array}{l}\text { Experiências de } \\
\text { enfermeiros iniciantes } \\
\text { com comunicação } \\
\text { paliativa e no final da } \\
\text { vida }\end{array}$ & $\begin{array}{l}\text { Explorar as perspectivas de } \\
\text { comunicação sobre } \\
\text { cuidados paliativos e de fim } \\
\text { de vida de enfermeiras } \\
\text { iniciantes em oncologia } \\
\text { pediátrica }\end{array}$ & $\begin{array}{l}\text { Estudo } \\
\text { qualitativo- } \\
\text { descritivo }\end{array}$ & $\begin{array}{l}\text { Nenhuma das enfermeiras relatou ter } \\
\text { frequentado ou concluído } \\
\text { anteriormente um programa } \\
\text { educacional focado em cuidados } \\
\text { paliativos ou de fim de vida } \\
\text { pediátrico. }\end{array}$ \\
\hline 14 & $\begin{array}{l}2016 \\
\text { Inglês } \\
\text { Pubmed }\end{array}$ & $\begin{array}{l}\text { Ajudar os pais a viver } \\
\text { com o buraco no } \\
\text { coração: o papel dos } \\
\text { prestadores de } \\
\text { cuidados de saúde e } \\
\text { instituições nas } \\
\text { jornadas de luto dos } \\
\text { pais }\end{array}$ & $\begin{array}{l}\text { Explorar o papel da equipe } \\
\text { de saúde e das instituições } \\
\text { médicas nas jornadas de } \\
\text { luto dos pais cujo filho } \\
\text { morreu devido ao câncer. }\end{array}$ & $\begin{array}{l}\text { Qualitativo- } \\
\text { quantitativo, } \\
\text { utilizando } \\
\text { grupo focal }\end{array}$ & $\begin{array}{l}\text { Nas narrativas foram destacados os } \\
\text { seguintes contextos: a importância de } \\
\text { relacionamentos fortes e contínuos } \\
\text { entre os provedores e famílias } \\
\text { enlutadas, da comunicação de alta } \\
\text { qualidade, o efeito das experiências } \\
\text { negativas entre provedores e famílias } \\
\text { sobre o luto dos pais e a importância }\end{array}$ \\
\hline
\end{tabular}




\begin{tabular}{|c|c|c|c|c|c|}
\hline & & & & & $\begin{array}{l}\text { do papel da instituição nas jornadas } \\
\text { de luto. }\end{array}$ \\
\hline 15 & $\begin{array}{l}2019 \\
\text { Inglês } \\
\text { Pubmed }\end{array}$ & $\begin{array}{l}\text { Percepção do apoio } \\
\text { no luto de } \\
\text { profissionais e } \\
\text { técnicos de unidades } \\
\text { de terapia intensiva } \\
\text { pediátrica em } \\
\text { hospitais públicos }\end{array}$ & $\begin{array}{l}\text { Expor a percepção de } \\
\text { sofrimento de suporte de } \\
\text { profissionais e técnicos de } \\
\text { unidades de terapia } \\
\text { intensiva pediátrica de } \\
\text { hospitais públicos, após o } \\
\text { óbito dos pacientes. }\end{array}$ & $\begin{array}{l}\text { Estudo } \\
\text { qualitativo } \\
\text { com } \\
\text { abordagem } \\
\text { fenomenoló } \\
\text {-gica. }\end{array}$ & $\begin{array}{l}\text { Os profissionais sentem-se pouco } \\
\text { amparados em suas tristezas após a } \\
\text { morte dos pacientes, onde existem } \\
\text { obstáculos para o enfrentamento da } \\
\text { situação. Embora enfrentar a morte } \\
\text { seja algo complexo, eles reconhecem } \\
\text { que podem gerar estratégias de } \\
\text { proteção. }\end{array}$ \\
\hline 16 & $\begin{array}{l}2019 \\
\text { Inglês } \\
\text { Pubmed }\end{array}$ & $\begin{array}{l}\text { Reações de luto e } \\
\text { estratégias de } \\
\text { enfrentamento de } \\
\text { médicos estagiários } \\
\text { que trabalham em } \\
\text { terapia intensiva } \\
\text { pediátrica }\end{array}$ & $\begin{array}{l}\text { Examinar o impacto } \\
\text { emocional e as reações de } \\
\text { luto à morte de uma criança } \\
\text { em médicos estagiários da } \\
\text { UTIP, juntamente com as } \\
\text { estratégias de } \\
\text { enfrentamento que eles } \\
\text { usaram. }\end{array}$ & $\begin{array}{l}\text { Estudo } \\
\text { prospectivo, } \\
\text { transversal e } \\
\text { observacio- } \\
\text { nal }\end{array}$ & $\begin{array}{l}\text { Destacaram-se temas proeminentes de } \\
\text { tristeza, desamparo, culpa, choque e } \\
\text { preocupação com a família } \\
\text { enlutada. Houve uso limitado de } \\
\text { estratégias de enfrentamento. Falar } \\
\text { com outro médico estagiário foi a } \\
\text { principal estratégia. }\end{array}$ \\
\hline 17 & $\begin{array}{l}2015 \\
\text { Inglês } \\
\text { Pubmed }\end{array}$ & $\begin{array}{l}\text { Definição de } \\
\text { significados durante } \\
\text { as reuniões de luto } \\
\text { entre pais e médicos } \\
\text { após a morte de uma } \\
\text { criança }\end{array}$ & $\begin{array}{l}\text { Identificar e descrever os } \\
\text { tipos de processos de } \\
\text { construção de significado } \\
\text { que ocorrem entre os pais } \\
\text { durante as reuniões de luto } \\
\text { com o médico intensivista } \\
\text { após a morte do filho }\end{array}$ & $\begin{array}{l}\text { Qualitativo, } \\
\text { com análise } \\
\text { de conteúdo }\end{array}$ & $\begin{array}{l}\text { Quatro processos principais de } \\
\text { definição de significado foram } \\
\text { identificados: construção de sentido, } \\
\text { descoberta de benefícios, vínculos } \\
\text { contínuos e reconstrução de } \\
\text { identidade. }\end{array}$ \\
\hline 18 & $\begin{array}{l}2015 \\
\text { Inglês } \\
\text { Pubmed }\end{array}$ & $\begin{array}{l}\text { Envolvimento de } \\
\text { profissionais de } \\
\text { cuidados de suporte } \\
\text { no atendimento ao } \\
\text { paciente no último } \\
\text { mês de vida }\end{array}$ & $\begin{array}{l}\text { Investigar a frequência } \\
\text { com que consultores de } \\
\text { cuidados paliativos, } \\
\text { especialistas em dor, } \\
\text { especialistas psicológicos e } \\
\text { cuidadores espirituais estão } \\
\text { envolvidos no cuidado de } \\
\text { pacientes no último mês de } \\
\text { vida e quais fatores estão } \\
\text { associados ao seu } \\
\text { envolvimento. }\end{array}$ & $\begin{array}{l}\text { Estudo } \\
\text { transversal }\end{array}$ & $\begin{array}{l}\text { O envolvimento de especialistas em } \\
\text { cuidados paliativos ou dor foi mais } \\
\text { comum em pacientes mais jovens, } \\
\text { com câncer e em pacientes que } \\
\text { morreram em casa. }\end{array}$ \\
\hline 19 & $\begin{array}{l}2011 \\
\text { Inglês } \\
\text { Pubmed }\end{array}$ & $\begin{array}{l}\text { Avaliações } \\
\text { individuais e em } \\
\text { grupo de enfermeiras } \\
\text { pediátricas de } \\
\text { cuidados paliativos, } \\
\text { de fim de vida e de } \\
\text { luto }\end{array}$ & $\begin{array}{l}\text { Descrever as classificações } \\
\text { dos enfermeiros pediátricos } \\
\text { sobre os objetivos e } \\
\text { problemas dos cuidados } \\
\text { paliativos. }\end{array}$ & $\begin{array}{l}\text { Estudo } \\
\text { transversal }\end{array}$ & $\begin{array}{l}\text { Os enfermeiros classificaram as } \\
\text { metas mais importantes dos cuidados } \\
\text { paliativos o controle da dor, } \\
\text { manutenção da qualidade de vida da } \\
\text { criança e a melhora da comunicação. }\end{array}$ \\
\hline 20 & $\begin{array}{l}2020 \\
\text { Inglês } \\
\text { Pubmed }\end{array}$ & $\begin{array}{l}\text { Experiência de } \\
\text { residente em pediatria } \\
\text { cuidando de crianças } \\
\text { no fim da vida em um } \\
\text { hospital infantil }\end{array}$ & $\begin{array}{l}\text { Quantificar a exposição de } \\
\text { residentes pediátricos a } \\
\text { mortes de pacientes e o } \\
\text { contexto dessas exposições. }\end{array}$ & $\begin{array}{l}\text { Estudo } \\
\text { retrospectiv } \\
\text { o e } \\
\text { quantitativo }\end{array}$ & $\begin{array}{l}\text { A maioria das mortes ocorreu na } \\
\text { UTIN ( } 30 \% \text { de todas as mortes); no } \\
\text { entanto, a exposição do residente ao } \\
\text { cuidado de fim de vida ocorreu mais } \\
\text { comumente na UTIP. }\end{array}$ \\
\hline 21 & $\begin{array}{l}2014 \\
\text { Inglês } \\
\text { CINAHL }\end{array}$ & $\begin{array}{l}\text { Falando com a criança } \\
\text { falecida: Perspectivas } \\
\text { dos profissionais de } \\
\text { saúde australianos em } \\
\text { cuidados pediátricos } \\
\text { ao fim da vida }\end{array}$ & $\begin{array}{l}\text { Discutir a prática dos } \\
\text { profissionais de saúde e } \\
\text { pais em falar com uma } \\
\text { criança após a morte }\end{array}$ & $\begin{array}{l}\text { Estudo } \\
\text { qualitativo }\end{array}$ & $\begin{array}{l}\text { Para os profissionais de saúde, } \\
\text { conversar com uma criança após a } \\
\text { morte foi significativo. Pesquisas } \\
\text { afirmam que, para os pais, essa ação é } \\
\text { parte integrante do processo de } \\
\text { despedida de um filho falecido } \\
\text { juntamente com o banho e o curativo } \\
\text { após a morte. }\end{array}$ \\
\hline
\end{tabular}




\begin{tabular}{|c|c|c|c|c|c|}
\hline 22 & $\begin{array}{l}2015 \\
\text { Inglês } \\
\text { CINAHL }\end{array}$ & $\begin{array}{l}\text { Morte e morrer } \\
\text { pediátricos: } \\
\text { explorando estratégias } \\
\text { de enfrentamento de } \\
\text { profissionais de saúde } \\
\text { e percepções da } \\
\text { prestação de apoio }\end{array}$ & $\begin{array}{l}\text { Explorar as percepções dos } \\
\text { profissionais de saúde sobre } \\
\text { o apoio ao luto em relação à } \\
\text { perda de um filho. }\end{array}$ & $\begin{array}{l}\text { Estudo } \\
\text { qualitativo }\end{array}$ & $\begin{array}{l}\text { Para os profissionais de saúde, as } \\
\text { construções em torno do } \\
\text { enfrentamento emergiram como apoio } \\
\text { de pares, estratégias pessoais de } \\
\text { enfrentamento, apoio familiar, } \\
\text { impacto físico do apoio e crenças } \\
\text { espirituais. }\end{array}$ \\
\hline 23 & $\begin{array}{l}2017 \\
\text { Inglês } \\
\text { CINAHL }\end{array}$ & $\begin{array}{l}\text { O Impacto da } \\
\text { Formação em } \\
\text { Cuidados Paliativos } \\
\text { Pediátricos nas } \\
\text { Atitudes de Morte dos } \\
\text { Profissionais de } \\
\text { Saúde }\end{array}$ & $\begin{array}{l}\text { Explorar o impacto de um } \\
\text { programa de treinamento } \\
\text { em cuidados paliativos } \\
\text { pediátricos nas atitudes de } \\
\text { morte de uma equipe } \\
\text { multidisciplinar de } \\
\text { profissionais de saúde. }\end{array}$ & $\begin{array}{l}\text { Estudo } \\
\text { quantitativo }\end{array}$ & $\begin{array}{l}\text { O confronto com a doença incurável } \\
\text { das crianças e a morte inevitável pode } \\
\text { gerar atitudes mistas em relação à } \\
\text { morte. Mais pesquisas são necessárias } \\
\text { para explorar o processo pelo qual as } \\
\text { mudanças nas atitudes de morte } \\
\text { ocorrem ao longo do tempo. }\end{array}$ \\
\hline 24 & $\begin{array}{l}2019 \\
\text { Inglês } \\
\text { CINAHL }\end{array}$ & $\begin{array}{l}\text { Análise temática das } \\
\text { percepções de } \\
\text { profissionais de saúde } \\
\text { sobre morte pediátrica }\end{array}$ & $\begin{array}{l}\text { Compreender melhor como } \\
\text { os membros da equipe de } \\
\text { assistência interprofissional } \\
\text { percebem e vivenciam as } \\
\text { situações de final de vida } \\
\text { neonatal e pediátrica }\end{array}$ & $\begin{array}{l}\text { Quantitativo } \\
\text {-qualitativo }\end{array}$ & $\begin{array}{l}\text { Vários fatores contribuem para a } \\
\text { forma como os prestadores de } \\
\text { cuidados interprofissionais percebem } \\
\text { as experiências de cuidados de fim de } \\
\text { vida para pacientes } \\
\text { neonatais/pediátricos. }\end{array}$ \\
\hline 25 & $\begin{array}{l}2011 \\
\text { Inglês } \\
\text { CINAHL }\end{array}$ & $\begin{array}{l}\text { Avaliação de uma } \\
\text { intervenção de } \\
\text { acompanhamento de } \\
\text { luto para pais } \\
\text { enlutados e suas } \\
\text { experiências de apoio } \\
\text { após a morte de um } \\
\text { filho - um estudo } \\
\text { piloto }\end{array}$ & $\begin{array}{l}\text { Avaliar a eficácia de um } \\
\text { programa de intervenção } \\
\text { para pais enlutados e suas } \\
\text { experiências }\end{array}$ & $\begin{array}{l}\text { Estudo } \\
\text { controlado e } \\
\text { aleatório }\end{array}$ & $\begin{array}{l}\text { O apoio recebido através do programa } \\
\text { foi percebido como útil no } \\
\text { enfrentamento do luto e os pais } \\
\text { avaliaram a intervenção de maneira } \\
\text { favorável. }\end{array}$ \\
\hline 26 & $\begin{array}{l}2013 \\
\text { Inglês } \\
\text { CINAHL }\end{array}$ & $\begin{array}{l}\text { Um consenso para a } \\
\text { mudança: } \\
\text { perspectivas dos pais } \\
\text { e profissionais sobre o } \\
\text { cuidado das crianças } \\
\text { no fim da vida }\end{array}$ & $\begin{array}{l}\text { Investigar as perspectivas } \\
\text { de profissionais de saúde e } \\
\text { assistência social sobre o } \\
\text { desenvolvimento de } \\
\text { serviços para crianças com } \\
\text { condições limitantes de vida } \\
\text { no final da vida, usando } \\
\text { questões identificadas por } \\
\text { pais enlutados como } \\
\text { prioridades. }\end{array}$ & $\begin{array}{l}\text { Qualitativo, } \\
\text { utilizando a } \\
\text { técnica de } \\
\text { grupo } \\
\text { nominal em } \\
\text { grupos } \\
\text { focais }\end{array}$ & $\begin{array}{l}\text { O encaminhamento tardio para } \\
\text { cuidados paliativos e a falta de } \\
\text { serviços na comunidade dominaram } \\
\text { os relatos de pais cujos filhos } \\
\text { apresentavam doenças não malignas, } \\
\text { mas não foram priorizados pelos } \\
\text { profissionais. }\end{array}$ \\
\hline
\end{tabular}

Fonte: Autores.

\section{Discussão}

Durante a análise das publicações os principais temas encontrados foram agrupados por similaridade em três grupos com intuito de facilitar a discussão. A saber: "o processo de formação como facilitador para lidar com o processo de morte e morrer", "a vivência dos profissionais diante do luto da família em pediatria" e "terminalidade e cuidados paliativos em pediatria“.

\subsection{O processo de formação como facilitador para lidar com o processo de morte e morrer}

Ficou evidente que a vivência da equipe de saúde no acompanhamento do processo de morte e morrer em unidades de terapia intensiva pediátrica não é suficiente para que os profissionais consigam aceitar a morte de uma criança, pois o fim dessa vida gera sentimentos como culpa e fracasso nos profissionais, levando-os inclusive ao processo de negação da morte (Souza \& Conceição, 2018). 
As publicações apontaram que os profissionais empregam estratégias físicas, emocionais, espirituais e de resolução de problemas para continuar a desempenhar o seu papel de forma eficaz e para proteger sua sensação contínua de bem-estar. Ainda que a terminalidade faça parte do cotidiano desses profissionais, a mesma permanece incompreendida, principalmente na pediatria, em que o morrer geralmente é considerado um evento antinatural (Forster \& Hafiz, 2015; Souza \& Conceição, 2018; Forster \& Windsor, 2014).

Sentir-se preparado para lidar com o processo de morte e o morrer talvez seja algo inalcançável também para o aluno de pós-graduação pela própria prerrogativa do processo de formação ao promover a extensão da vida, conforme pôde ser percebido nos achados desta revisão. Embora a literatura aponte que as disciplinas dos programas de pós-graduação apresentamse deficientes quanto à abordagem do tema da morte, as partes práticas do programa juntamente com as discussões interdisciplinares podem possibilitar aos discentes reflexões mais profundas e complexas sobre este assunto (Barbosa \& Carvalho, 2016).

A pós-graduação nos moldes de residência é encarada como uma excelente oportunidade para a complementaridade da formação na graduação, considerando, porém, que esta também apresenta lacunas em relação à formação para o tema da terminalidade, especialmente em pediatria (Lima \& Andrade, 2017).

Constatou-se nas publicações que grande parte dos profissionais da saúde apontam que a temática exposta esteve presente em seu processo de formação como algo distante, um acontecimento possível na teoria em decorrência de condições orgânicas desfavoráveis, mas não como algo real, que acontece diante do profissional. Alguns autores apontam como razão para esse distanciamento nas grades curriculares da área da saúde a própria dificuldade dos docentes em lidar com o tema, o que acaba por perpetuar a falta de discussão e reflexão sobre a morte (Barbosa \& Carvalho, 2016).

Alguns estudos discutiram a necessidade de instituições formadoras e hospitalares ofertarem capacitações sobre o processo de morte e morrer, já que a terminalidade na infância é considerada um processo complexo e de difícil aceitação. Desta forma, fica nítido que abordar este assunto ainda durante o processo de formação, modifica a forma que estes profissionais lidam com a temática na prática assistencial (Scaratti, et al., 2019; Trowbridge, et al., 2020).

\subsection{A vivência dos profissionais diante do luto da família em pediatria}

$\mathrm{Na}$ análise sobre a temática, ficou evidente que os sentimentos emanados diante da morte em pediatria são complexos por estimularem a reflexão sobre algo que é intrínseco no homem: sua finitude. A morte de uma criança pode ter efeitos emocionais significativos na equipe de saúde responsável por seus cuidados. Em uma UTIP, esses sentimentos parecem ser mais caóticos, tendo em vista a preparação e o esforço dos profissionais de saúde para a manutenção da vida da criança, bem como sua interação com seus familiares e o pesar perante o fïm de uma existência que mal começou. Além disso, as decisões éticas no final da vida são problemas frequentes que os profissionais de saúde enfrentam. Em seu papel social de contenção e assistência, muitas vezes se sentem oprimidos pela dor e até pelo medo que a morte possa causar (Silva, et al., 2010; Troncoso, et al., 2020; Ffrench-O'carroll, et al., 2019).

No relato da literatura mostrou que o enfrentamento da morte na pediatria é uma situação extremamente delicada e, portanto, requer uma abordagem cercada de muita cautela e sensibilidade. Não obstante seja um evento mais comum dentro de uma UTI, persistem as dificuldades em seu manejo adequado. Lidar com a morte é uma questão extremamente complicada e dolorosa. Porém, lidar com esta situação se torna muito pior e penoso para as famílias, quando a vida que está em risco é a de uma criança. Essa reação se pauta, em grande parte, na concepção de tratar-se de um indivíduo que ainda não viveu o suficiente, contrariando, assim, a lógica do que seria o ciclo natural e completo da vida humana (Marques, et al., 2013).

Dentre os artigos selecionados, três pesquisas relataram que a morte de uma criança é considerada um evento inimaginável e devastador, descrita como a tristeza mais difícil e profunda que pais e mães podem experimentar. Vivenciar a 
morte de um filho é um processo complexo e difícil de enfrentar, pois se trata de uma experiência individual, privada e intransferível. Famílias que vivem o luto frequentemente experimentam sentimentos debilitantes de choque, impotência e culpa. Além disso, é preciso frisar que para muitos pais, a jornada de luto pode ser mais intensa e prolongada, resultando em diversos agravos à saúde, incluindo o luto complicado (Snaman, et al., 2016; Garcia \& Riveros, 2013; Aho, et al., 2011).

O luto complicado é uma condição patológica caracterizada por sintomas persistentes decorrentes do sofrimento de perda. Entre os sintomas do luto complicado pode-se destacar intenso desejo pelo ente falecido, sensação de choque e descrença, raiva e amargura, pensamentos intrusivos e preocupantes com o falecido, negação de lembranças da perda ou busca excessiva de proximidade, intensa solidão e sentimento de que a vida após esta perda não tem nenhum propósito ou significado. Muitos desses sintomas também ocorrem com o luto como processo natural e constituinte de nossas vidas; entretanto, quando o luto complicado se desenvolve, esses sintomas são intensos, prolongados e debilitantes (Meert, et al., 2015).

Quanto ao luto dos profissionais de saúde, segundo os achados da revisão, é preciso destacar que os sentimentos durante o acompanhamento da morte e do morrer de pacientes pediátricos são variados e exigem um preparo psicológico e emocional. A morte de uma mesma criança pode ser sentida de diferentes formas de acordo com a vivência de cada profissional. A compaixão, indiferença, impotência, ansiedade, culpa, negação, envolvimento emocional, empatia, angústia e tristeza são os mais comuns entre profissionais que vivenciam diretamente este processo. Tal situação é agravada pela sensação de baixo suporte social e pouco preparo para o enfrentamento da morte e apoio à família do paciente (Souza \& Conceição, 2018; Vega-Veja, et al., 2019; Kukora, et al., 2019).

Conforme demonstrado em uma pesquisa, na qual analisou a atuação dos-profissionais de saúde residentes em contato com a morte e o morrer, faz-se necessário que se ofertem espaços de cuidado a esses profissionais nas instituições hospitalares, que permitam que estes falem de suas angústias e das dores decorrentes da vivência com a morte e o morrer, a fim de realizarem um cuidado que não seja causador de sofrimento. Tais espaços possibilitariam também debates, discussões e reflexões, centradas na preparação psicológica e emocional e nas relações interpessoais que emergem na prática de cuidar, visando o desenvolvimento de habilidades e atitudes que facilitariam as intervenções junto ao paciente e sua família (Lima \& Andrade, 2017).

\subsection{Terminalidade e os cuidados paliativos em pediatria}

Em oncologia pediátrica, trabalha-se muito com cuidados paliativos, os quais devem ser iniciados a partir do diagnóstico de doença que ameace a vida e possuem foco em prevenir e aliviar o sofrimento relacionado à doença e ao tratamento, bem como em promover a qualidade de vida. Logo, não é recomendado citar cuidados paliativos remetendo o diagnóstico à noção de terminalidade. Da mesma forma, a ideia da impossibilidade de cura é então substituída pelo conceito de tratamentos que modifiquem a doença, afastando, portanto, a noção equivocada de "não ter mais o que fazer" (Pacheco \& Goldim, 2019).

Nesse sentido, como constatado na literatura, o tratamento do câncer infantil é extenso e a interação cotidiana da equipe de saúde com as crianças e seus familiares obriga esses profissionais a vivenciarem as expectativas do tratamento e sofrerem verdadeiramente quando se esgotam todas as possibilidades de cura (Silva, et al., 2015).

Quando as possibilidades de cura de uma criança em situação de terminalidade se esgotam, é indicado iniciar os cuidados paliativos. Atualmente se fazem muitos esforços para mudar a cultura dos cuidados ao paciente que vivencia o processo de terminalidade, entendendo-a como o respeito à existência de diferentes visões do portador de neoplasia, familiar e profissional e ao modo holístico de cuidar (Nascimento, et al., 2013; Tubbs-Cooley, et al., 2011).

Segundo Brinkman-Stoppelenburg et al. (2015), nos últimos meses de vida, muitos pacientes sofrem de múltiplos sintomas e problemas. Desta forma, o cuidado paliativo é uma abordagem que promove a qualidade de vida de pacientes e de suas famílias diante de doenças graves e que ameaçam a vida, objetivando a prevenção e o alívio do sofrimento pela dor ou de outros problemas físicos, psicossociais e espirituais. A abordagem paliativa busca manter a dignidade do paciente que vivencia 
o processo de terminalidade e dar suporte à família na doença e no luto (Forster \& Windsor, 2014; Nascimento, et al., 2013; J. Price, et al., 2013).

Os achados apontam que os profissionais de saúde possuem pouca experiência na realização dos cuidados paliativos e têm dificuldade em lidar com os sentimentos, sentindo-se, às vezes, impossibilitados de agir mediante as angústias dos envolvidos e com o processo de morte e o morrer. É necessário que a equipe de saúde, independentemente de seus anos de experiência, seja competentes e se sinta à vontade para envolver os familiares no cuidado e nas discussões sobre cuidados paliativos e processo de morte e morrer (Hendricks-Ferguson, et al., 2015).

Segundo Souza et al. (2013), oferecer uma morte digna é um desafio, pois envolve o equilíbrio de múltiplas perspectivas e necessidades da criança, da família e dos próprios profissionais. Além disso, evidenciou-se que a experiência do cotidiano em cuidados paliativos e terminalidade fortalece os profissionais de saúde, mas é necessário aprofundamento sobre esses temas, em especial durante o processo de formação e também na educação continuada (Nascimento, et al., 2013; Scaratti, et al., 2019; Bouri, et al., 2017).

Destaca-se que essa Revisão Integrativa apresentou evidências importantes sobre a temática, contudo, identificou-se como limitação metodológica a escassez de publicações que analisem as peculiaridades da formação dos profissionais de saúde a nível acadêmico e prático, com atividades de intervenção para treinamento, referentes ao enfrentamento do processo de morte e morrer em pediatria.

Os achados dessa pesquisa foram direcionados pelo recorte temporal estabelecido e as estratégias de busca, o que pode ser considerado um limitador para a possibilidade de eleição de pesquisas relevantes para compor a revisão.

\section{Considerações Finais}

O fato da morte ainda ser considerada um tabu para a sociedade acaba por perpetuar a falta de discussão e reflexão sobre o processo de morte e morrer no meio acadêmico. Desta forma, os profissionais de saúde não se sentem efetivamente capacitados para lidar com o processo de morte e morrer em pediatria, principalmente pela falta de contato com esta temática durante a graduação e até mesmo na pós-graduação e posteriormente, pela falta de apoio nas instituições assistenciais.

Esta revisão contribui por evidenciar a necessidade de criação de treinamentos, capacitação, espaços de debates, discussões e reflexões nas instituições assistenciais e acadêmicas, que permitam que os profissionais de saúde desenvolvam habilidades e falem de suas angústias e dores decorrentes da vivência com a morte e o morrer, a fim de realizarem um cuidado que não seja causador de sofrimento e encontrem formas saudáveis de ressignificar a perda de um paciente pediátrico.

Nesse sentido, sugere-se que pesquisas futuras sejam realizadas sobre esta temática para endossar a discussão e a reflexão sobre a terminalidade no meio acadêmico a fim de que a equipe de saúde lide com o processo de morte e morrer de forma mais natural, compreendendo que a morte faz parte de seu contexto de trabalho e deve ser vivenciada de forma leve.

\section{Referências}

Aho, A. L., Tarkka, M. T., Astedt-kurki, P., Sorvali, L., \& Kaunonen, M. (2011). Evaluating a bereavement follow-up intervention for grieving fathers and their experiences of support after the death of a child--a pilot study. Death Stud. 35(10):879-904. https://doi.org/10.1080/07481187.2011.553318

Alves, M. V. M. F. F., Nunes, D. S., Bronzatto, C. H. L., Trevizani M. J. N., \& Toso, L. A. R. (2012). Morte e morrer em unidade de terapia intensiva pediátrica: percepção dos profissionais de saúde. Cogitare Enfermagem, 17, 543-548. http://dx.doi.org/10.5380/ce.v17i3.29296

Barbosa, L. \& Carvalho, I. S. (2016). A perspectiva de residentes sobre a morte e seu reflexo na relação com os pacientes. Rev. SBPH, 19, 107-128. http://pepsic.bvsalud.org/scielo.php?script=sci_arttext\&pid=S1516-08582016000200008

Bouri, M., Papadatou, D., Koukoutsakis, P., Bitsakou, P., \& Kafetziz, D. (2017). The Impact of Pediatric Palliative Care Training on the Death Attitudes of Health Professionals. International Journal of Caring Sciences, 10, 676-681. https://www.researchgate.net/publication/320345385 
Brinkman-Stoppelenburg, A., Onwuteaka-Philipsen, B. D., \& Van, D. H. A. (2015). Involvement of supportive care professionals in patient care in the last month of life. Support Care Cancer. ;23(10):2899-906. http://dx.doi.org/10.1007/s00520-015-2655-3

Ffrench-o'Carrol, R., Feeley, T., Crowe, S., \& Doherty, E. M. (2019). Grief reactions and coping strategies of trainee doctors working in paediatric intensive care. Br J Anaesth.; 123(1):74-80. http://dx.doi.org/10.1016 / j.bja.2019.01.034

Forster, E. M. \& Hafiz, A. (2015). Paediatric death and dying: exploring coping strategies of health professionals and perceptions of support provision. Int J Palliat Nurs.; 21(6):294-301. http://dx.doi.org/10.12968/ijpn.2015.21.6.294

Forster, E. M. \& Windsor, C. (2014). Speaking to the deceased child: Australian health professional perspectives in paediatric end-of-life care. Int J Palliat Nurs. ;20(10):502-8. http://dx.doi.org/10.12968/ijpn.2014.20.10.502

Garcia, S. V. \& Rivas, R. E. (2013). Experiência de enfermeiros pediátricos intensivos na morte de uma criança: experiências, lesão, aspectos bioéticos. Ciência. doente, Concepción, 19, 111-124. http://dx.doi.org/10.4067/S0717-95532013000200011.

Hendricks-Ferguson, V. L., Sawin, K. J., Montgomery, K., Dupree, C., Phillips-Salimi, C. R., CARR, B., \& Haase, J. E. (2015). Novice Nurses' Experiences With Palliative and End-of-Life Communication. J Pediatr Oncol Nurs. ;32(4):240-52. http://dx.doi.org/10.1177/1043454214555196

Kukora, S., Keefer, P., Pituch, K., \& Firn, J. (2019). Thematic Analysis of Interprofessional Provider Perceptions of Pediatric Death. Journal of Pediatric Nursing 47: 92-99. http://dx.doi.org/10.1016 / j.pedn.2019.05.002

Lima, M. J. V. \& Andrade, N. M. (2017). A atuação do profissional de saúde residente em contato com a morte e o morrer. Saude soc., 26, 958-972. https://www.scielo.br/scielo.php?pid=S010412902017000400958\&script=sci_abstract\&tlng=pt

Lima, R., Borsatto, A. Z., Vaz, D. C., Pires, A. C. F., Cypriano, V. P., \& Ferreira, M. A. (2017). A morte e o processo de morrer: ainda é preciso conversar sobre isso. Rev Min Enferm; 21:e-1040. http://www.dx.doi.org/10.5935/1415-2762.20170050

Marques, C. D. C., Veronez, M., Sanches, M. R., \& Higarashi, I. H. (2013). Significados atribuídos pela equipe de enfermagem em unidade de terapia intensiva pediátrica ao processo de morte e morrer. REME rev. min. Enferm; 17(4): 823-830. http://www.dx.doi.org/10.5935/1415-2762.20130060

Meert K. L., Eggly S., Kavanaugh K., Berg R. A., Wessel D. L., Newth C. J., Shanley T. P., Harrison R., Dalton H., Dean J. M., Doctor A., Jenkins T., \& Park C. L (2015). Meaning making during parent-physician bereavement meetings after a child's death. Health Psychol. 34(4):453-61. http://www.dx.doi.org/10.1037/hea0000153.

Nascimento, D. M., Rodrigues, T. G., Soares, M. R., Rosa, M. L. S., Viegas, S. M. F., \& Salgado, P. O. (2013). Experiência em cuidados paliativos à criança portadora de leucemia: a visão dos profissionais. Ciênc. saúde coletiva, 18, 2721-2728. https://www.redalyc.org/articulo.oa?id=63028227027

Pacheco, C. L. \& Goldim, J. R. (2019). Percepções de equipe interdisciplinar sobre cuidados paliativos em oncologia pediátrica. Rev. Bioét., 27, 67-75. http://dx.doi.org/10.1590/1983-80422019271288

Poles, K. \& Bousso, R. S. (2006). Compartilhando o processo de morte com a família: uma experiência de enfermeira na UTI pediátrica. Rev. Latino-Am. Enfermagem, 14, 207-213. http://dx.doi.org/10.1590/S0104-11692006000200009

Price, J., Jordan, J., \& Prior, L. (2013). A Consensus for Change: Parent and Professional Perspectives on Care for Children at the End-Of-Life. Questões em Enfermagem Pediátrica Abrangente 36 (1-2). http://dx.doi.org/10.3109 / 01460862.2013 .779765

Scaratti, M., Oliveira, D.R., Rós, A. R., Debon, R., \& Baldissera, C. (2019). Do Diagnóstico a Terminalidade: Enfrentamento da Equipe Multiprofissional na Oncologia Pediátrica. Rev Fund Care Online. 311-316. http://dx.doi.org/10.9789/2175-5361.2019.v11i2.311-316

Silva, A. F., Issi, H. B., Motta, M. G. C., \& Botene, D. Z. A. (2015). Cuidados paliativos em oncologia pediátrica: percepções, saberes e práticas na perspectiva da equipe multiprofissional. Rev. Gaúcha Enferm., 36, 56-62. http://dx.doi.org/10.1590/1983- 1447.2015.02.46299

Silva, L. C. S. P., Valença, C. N., \& Germano, R. M. (2010). Percepções dos profissionais de enfermagem intensiva frente a morte do recém-nascido. Rev. bras. enferm., 63, 238-242. http://dx.doi.org/10.1590 / S0034-71672010000200011

Snaman, J. M., Kaye, E. C., Torres, C., Gibson, D. V., \& Baker, J. N (2016). Helping parents live with the hole in their heart: The role of health care providers and institutions in the bereaved parents' grief journeys. Cancer. 1;122(17):2757-65. http://dx.doi.org/10.1002 / cncr.30087

Souza, L. F., Misko, M. D., Silva, L., Poles, K., Santos, M. R., \& Bousso, R. G. (2013). Morte digna da criança: percepção de enfermeiros de uma unidade de oncologia. Rev. esc. enferm. USP, 47, 30-37. http://www.redalyc.org/articulo.oa?id=361033324004

Souza, M. T., Silva, M. D., \& Carvalho, R. (2010). Revisão Integrativa: O que é e como fazer. Einstein, 8(1 Pt 1):102-6. http://www.scielo.br/pdf/eins/v8n1/pt_1679-4508-eins-8-1-0102

Souza, P. S. N. \& Conceição, A. O. F. (2018). Processo de morte em unidade de terapia intensiva pediátrica. Rev. Bioét., 26, 127-134. http://dx.doi.org/10.1590/1983-80422018261234

Troncoso, M. P., Romero, B. P., \& Schnake, M. C. (2020). Reflexión bioética al cuidar un niño que enfrenta la muerte. Rev. Bioét., 28, 281-287. http://dx.doi.org/10.1590/1983-80422020282390

Trowbridge, A., Bamat, T., Griffis, H., McConathey, E., Feudtner, C., \& Walter, J. K. (2020). Pediatric Resident Experience Caring for Children at the End of Life in a Children's Hospital. 20 (1): 81-88. http://dx.doi.org/10.1016/j.acap.2019.07.008

Tubbs-Cooley, H. L., Santucci, G., Kang, T. I., Feinstein, J. A., Hexem, K. R., \& Feudtner, C. (2011). Avaliações individuais e em grupo de enfermeiras pediátricas sobre cuidados paliativos, de fim de vida e de luto. J Palliat Med.; 14 (5): 631-7. http://dx.doi.org/10.1089/jpm.2010.0409 
Research, Society and Development, v. 10, n. 9, e2310917790, 2021

(CC BY 4.0) | ISSN 2525-3409 | DOI: http://dx.doi.org/10.33448/rsd-v10i9.17790

Veja-vega, P., Rodríguez, R. G., Encina, M. E. L., González, E. A., Aldunate, P. C., Suárez, L. R., \& Briones, X. G. (2019). Perception of support in professional's and technician's grief of pediatric intensive care units in public hospitals. Rev Chil Pediatr. 90(4):429-436. http://dx.doi.org/10.32641 / rchped.v90i4.1010

Whittemore, R. \& Knafl, K. The Integrative Review: Updated Methodology. J AdvNurs, 52(5):546-53. https://doi.org/10.1111/j.1365-2648.2005.03621.x 